\title{
Sheltering the homeless
}

I n August 2006, concerns were raised across the country in response to the announcement of cutbacks to the federal government's homelessness funding program. ${ }^{1}$ Advocates for the homeless remain concerned that the current government intends to eliminate federal programs addressing homelessness, although this was quickly denied by the federal Minster of Human Resources and Social Development Diane Finley. The loss of federal government leadership in tackling homelessness would not only affect homeless shelters but would have an equally negative effect on hospitals and the health care system. There is a belief that the long-term investments in affordable and supported housing, mental health services and income support that are required to end homelessness in Canada will be unpalatable to a government positioning itself to win a majority government.

Historically, shelters for the homeless date back to a charitable model of offering a helping hand to people in temporary crisis. Decades of changes to health and social policy combined with a decline in family and community support systems have left thousands of the most vulnerable Canadians relying on emergency shelters and associated services for survival. Although many who come to a shelter do need short-term services, in every urban setting at least 10\% of those who use shelters have been homeless for more than a year. This is the population that is most vulnerable to the degradation of homeless services, and this is the population associated with high health care and judicial costs in the absence of alternative systems. Our social safety net, which is intended to provide protection to the vulnerable, increasingly fails those with the greatest needs, resulting in unnecessary costs to the health, social and legal sectors and associated human suffering.

The health care system once provided a fail-safe mechanism for this population. Those who could not live with the support available in the community lived in institutions. This model was deemed too costly to the taxpayer and undeniably prevented the individual from enjoying those basic rights accorded to all citizens. However, institutional care did provide for some of this population's needs, keeping them safe and managing costs associated with their care. Unfortunately, living in a shelter without appropriate support is associated with costly and ineffective emergency health care and judicial services, while providing little benefit to the individual or society. We have accepted a model of cost ineffectiveness and social isolation rather than taking responsibility for affordable housing and the necessary services to provide a dignified life for our most vulnerable citizens. ${ }^{2,3}$
Health care advocates who work with the homeless are frustrated by the failure of government policy to reflect the evidence about effectiveness. Despite the overwhelming evidence that a range of harm reduction strategies saves lives and health care costs, government policy continues to be influenced by other arguments and agendas. Policies that deem one vulnerable group (e.g., drug addicts) to be unworthy of aspects of care place all our vulnerable groups (e.g., immigrants, the elderly, people with developmental delays) at risk. Despite the evidence that affordable, supportive housing with appropriate long-term health care is an effective way to reduce homelessness for vulnerable populations, governments are reluctant to commit the necessary resources. Although short-term access to housing with mental health and other health care services and private market housing solutions are politically popular, the evidence indicates that they are ineffective. ${ }^{4}$ Unfortunately, social policy that is based upon evidence is counter to that which is more politically acceptable. The charitable sector cannot nor should not take full responsibility for funding the care of those with the most complex needs in our society. The contributions of the charitable sector in the area of homelessness are significant and invaluable, but they are not a substitute for policy based on scientific evidence. Charitable groups should not be expected to formulate and implement a comprehensive national policy for the homeless. This is the role of government as our elected representatives.

\section{Wendy Muckle}

Ottawa Inner City Health, Inc.

Jeffrey Turnbull

Department of Medicine

University of Ottawa

Ottawa, Ont.

This article has been peer reviewed.

\section{REFERENCES}

I. Statement by the Honourable Diane Finley, Minister of Human Resources and Social Development [press release]. Ottawa. August 17, 2006. Available: http://news .gc.ca/cfmx/view/en/index.jsp?articleid=233559 (accessed 2006 Oct I2).

2. Steve Pomeroy Focus Consulting Inc. Invest or subsidize: comparative subsidy cost of non-profit and private market units rent supplements in Ottawa 1978-2004. May 2005. Available: www.onpha.on.ca/affordable_housing_initiatives/fight_resources /doc/ottawa_final.pdf (accessed 2006 Oct 6).

3. Plumb JD. Homelessness: reducing health disparities [editorial]. CMAJ 2000;163:172-3

4. Kushel MB, Vittinghoff E, Hass JS. Factors associated with the health care utilization of homeless persons. JAMA 200I;285:200-6. 